University of Warwick institutional repository

This paper is made available online in accordance with

publisher policies. Please scroll down to view the document

itself. Please refer to the repository record for this item and our

policy information available from the repository home page for

further information.

To see the final version of this paper please visit the publisher's website.

Access to the published version may require a subscription.

Author(s): Page, Edward

Article Title: Intergenerational Justice and Climate Change

Year of publication: 1999

Link to published version: http://dx.doi.org/10.1111/1467-9248.00187

Publisher statement: The definitive version is available at www.blackwell-synergy.com 


\title{
Intergenerational Justice and Climate Change
}

\author{
EDWARD A. PAGE
}

University of Southampton $^{*}$

Global climate change has important implications for the way in which benefits and burdens will be distributed amongst present and future generations. As a result it raises important questions of intergenerational justice. It is shown that there is at least one serious problem for those who wish to approach these questions by utilising familiar principles of justice. This is that such theories often pre-suppose harm-based accounts of injustice which are incompatible with the fact that the very social policies which climatologists and scientists claim will reduce the risks of climate change will also predictably, if indirectly, determine which individuals will live in the future. One proposed solution to this problem is outlined grounded in terms of the notion of collective interests.

The issue of global climate change has attracted increasing interest amongst political scientists and theorists in recent years. The complex interactions amongst nation-states which have resulted from moves to construct world-wide, and legally binding, restrictions on greenhouse gas (GHG) emissions is a fascinating source of research for international relations theorists generally, and game theorists in particular. ${ }^{1}$ Moreover, the fact that the future costs of climate change are not expected to be shared evenly amongst nations has

\footnotetext{
* I would like to thank Andrew Williams, John Horton, and an anonymous referee of Political Studies for helpful comments on earlier versions of this article.

${ }^{1}$ For a game theoretical account of climate change politics, see Hugh Ward, 'Game Theory and the Politics of Global Warming: the State of Play and Beyond', Political Studies, 44, 5 (1996), 850-71; for the international relations perspective on climate change issues see M. Peterson, Global Warming and Global Politics, (London, Routledge, 1996).
} 
attracted the interest of theorists concerned with problems of global justice. ${ }^{2}$ However, one of the most striking set of questions raised by climate change concerns the way in which social, economic and cultural resources should be distributed across generations.

Recent evidence suggests, for example, that present levels of GHG emissions will have particularly grave consequences both for the integrity of the biosphere and for the well-being of its future human and non-human inhabitants. In its most recent assessment of the global climate change issue, the authoritative Intergovernmental Panel on Climate Change (IPCC) concluded not only that 'the balance of evidence suggests discernible human influence on climate change', ${ }^{3}$ but also that the long-term impact of climate change will have a predominantly, if not uniformly, adverse impact on the health, cultural life, and economic prosperity of future human populations. ${ }^{4}$ In fact, the IPCC went on to conclude that global climate change issues raise 'particular questions of equity between generations. $^{5}$

While the IPCC seem to take it largely for granted that climate change raises questions of intergenerational justice, there have been few systematic attempts to test the robustness of these assumptions (1) across different theories of distributive justice and (2) in the light of some perplexing problems associated with extending the scope of these theories beyond the realm of dealings between contemporaries of the same society.

\footnotetext{
${ }^{2}$ See M. Grubb, 'Seeking fair weather: ethics and the international debate on climate change', International Affairs, 71, 3 (1995), 463-96; H. Shue, 'Avoidable necessity: Global warming, international fairness, and alternative energy', in I. Shapiro and J. W. DeCew, eds., NOMOS XXXVII: Theory and Practice, (New York, New York University Press, 1995), 239-64; and H. Shue, 'The Unavoidability of Justice', in A. Hurrell and B. Kingsbury, eds., The International Politics of the Environment, (Oxford, Oxford University Press, 1992), pp.373-97.

${ }^{3}$ J.T. Houghton, M.C. Zinyowera, and R.H. Moss, eds., Climate Change 1995: The Science of Climate Change, (Cambridge, Cambridge University Press), 1996, p.5.

${ }^{4}$ See A.J. McMichael et al, 'Human Population Health', in R.T. Watson, eds., Climate Change 1995: Impacts, Adaptations, and Mitigation of Climate Change, (Cambridge, Cambridge University Press, 1996), pp. 564ff. It is worth noting that at least some of the IPCC's research findings are controversial. However, even those who are sceptical of the relevance of the IPCC's findings for questions of social justice, such as Wilfrid Beckerman, do not dispute the fact that climate change will impact upon the distribution of resources across generations to some extent. See W. Beckerman, Small is Stupid: Blowing the whistle on the greens, (London, Duckworth, 1995), pp.90ff.

${ }^{5}$ K.J. Arrow et al, 'Intertemporal Equity, Discounting and Economic Efficiency', in J.P Bruce, H. Lee, and E. Haites, eds., Climate Change 1995: Economic and Social Dimensions of Climate Change, (Cambridge, Cambridge University Press, 1996), p. 130. This conclusion is consistent with the text of the earlier United Nations Framework Convention on Climate Change, according to which those nations party to it 'should protect the climate system for the benefit of present and future generations of humankind, on the basis of equity and in accordance with their common but differentiated responsibilities and respective capabilities.' See United Nations Framework Convention on Climate Change, (London, HMSO Books, 1993), p.5.
} 
Regarding issue 2, for example, there appears to be a widely held conviction that activities which compound the climate change problem are unjust, or unethical, because they harm generations yet unborn. ${ }^{6}$ This paper argues, however, that a unique philosophical puzzle confronts those who wish to explain our responsibilities to future generations, for example regarding the climate change problem, in terms of the language of disadvantages and harms. The central problem developed is that it is unclear how exactly future persons can be harmed, or disadvantaged, by acts or social policies which are necessary conditions of their coming into existence. This presents a serious challenge, it will be argued, for a whole range of accounts of environmental, and intergenerational, justice which assume that actions or policies can only be wrong if they harm, disadvantage or victimise particular human or non-human animals (I call these identity-dependent accounts of justice).

In the next section, I outline briefly a prominent example of an identity-dependent theory of intergenerational justice. Next, I explain how this theory, by virtue of its identitydependent structure, seems unlikely to generate stringent duties of intergenerational justice - for example, duties which could explain why existing generations should sacrifice certain benefits in order to preserve the climate system for their remote descendants. Next, I argue that whereas we might appeal to an identity-independent theory of intergenerational justice in order to explain the basis of such duties, there are considerations which suggest that it would be worth seeing if some version of the identity-dependent view can be defended. Finally, I develop one line of thought which seeks to do precisely this, which is developed in terms of the notion of collective interests.

\section{Intergenerational justice as resource conservation}

One theory of intergenerational justice which seems consistent with the thought that existing generations owe it to their distant successors not to despoil the natural environment in general, and the climate system in particular, proposes that each generation should hand down to the next a no less abundant share of resources than that which it inherited from previous generations. According to an influential version of this theory proposed by Barry, the consumption of non-renewable natural resources over time 'should

\footnotetext{
${ }^{6}$ Onora O'Neill, for example, writes that 'by burning fossil fuels prodigally we accelerate the green-house effect and may dramatically harm successors, who can do nothing to us.' See O’Neill, Towards Justice and Virtue (Cambridge, Cambridge University Press, 1996), p.115.
} 
be compensated for in the sense that later generations should be left no worse off. . . than they would have been without the depletion. ${ }^{7}$ We might call this the resourcist view of intergenerational justice.

Barry comes to this resourcist view by the following line of thought. ${ }^{8}$ The fundamental issue for a theory of intergenerational justice, he thinks, is the appropriate consumption of non-renewable natural resources across time. When reserves of nonrenewable resources (such as oil or natural gas) are depleted, the costs of extracting and then using these resources to generate electricity to heat homes, power cars, and run machinery are increased for future generations. There are also costs imposed upon these generations in virtue of the side-effects of depleting these resources, such as global climate change, air pollution and destruction of the ozone layer. As a consequence, it is crucial to establish how much existing generations may deplete stocks of non-renewable resources without violating the requirements of intergenerational justice.

It would be unfair to require existing generations to leave all non-renewable resources untouched for the sake of future generations (that is to consume nothing); neither would it be possible for each generation to replicate in every detail the nonrenewable resources it exhausts. However, it would appear to be a sound principle to aim for that existing generations ought not act so as to worsen the position of future generations by depleting non-renewable resources with no compensatory action or recompense.

The idea of making recompense, however, typically leaves it open for a given compensation for a depleted resource, $X$, to be compensated by the provision of a given commensurable resource, $Y$ - so long as this compensation enables the recipient to be no worse off than they would have been had the original resource, $\mathrm{X}$, not been used up. Perhaps the most obvious example of such compensation in the intergenerational context would be the way in which improvements in technology (energy efficiency, for example) appear to compensate for losses of natural non-renewable resources (energy resources such as coal, for example).

So long as we regard the climate system as a sort of 'open access resource' in its own right, it appears that resourcism will generate extensive obligations on the part of

\footnotetext{
${ }^{7}$ B. Barry, 'The Ethics of Resource Depletion', in Democracy, Power and Justice, (Oxford, Clarendon, 1989), p.519 - emphasis added.

${ }^{8}$ Barry, 'The ethics of resource depletion', pp.515ff.
} 
existing generations (1) not to damage the climate system by continued profligate GHG emissions, (2) not to deplete non-renewable natural resources which are sources of GHGs, or (3) not to bring about the destruction of certain natural resources (such as coastal land) through climate change unless these actions are offset by an appropriate amount of compensation.

\section{Intergenerational resourcism and the non-identity problem}

As a test for Barry's theory of intergenerational justice, next consider the case of the Two Climate Change Policies:

A choice must be made between two mutually exclusive, and exhaustive, climate change policies. The first, the Depletion Policy, involves a continuing commitment to non-renewable energy sources and associated high levels of GHG emissions with no commitment to any offsetting compensation measures for the sake of future generations. The second, the Conservation Policy, involves a move towards heavier reliance on renewable energy sources, tight restrictions on GHG emissions, as well as certain compensatory measures for the sake of future generations (such as increased investment in schemes to protect coastal areas which are vulnerable to climate change induced sea-level rises).

Adopting the Conservation policy, it is known, will limit the damage caused by climate change. The Depletion Policy, though, would demand little or no sacrifice of present persons, and, because it would not check the increase of human originating GHG emissions, would have, relative to the Conservation Policy, more serious repercussions on human well-being (as associated with the social costs of adapting to higher temperatures and sea-levels, for example).

In fact, it is known with some confidence that, after one or two centuries after the choice has been made, many of the people who would later live if the Depletion Policy is chosen will enjoy a significantly lower quality of life than those who would live if the Conservation Policy is adopted. However, the longterm disadvantages associated with choosing Depletion are not so severe that the persons who will come into existence if this option is chosen will lead lives 
which are not worth living - i.e. they will not on balance regret that these people had ever been born.

Next, consider the following line of argument which seems to undermine the reasoning behind many people’s intuitive objections to the Depletion Policy. ${ }^{9}$

As a consequence of the profound impact it will have on even the smallest details of all people's lives, whatever decision is made in regard to the Conservation and Depletion policies will predictably, if indirectly, affect who mates with whom and when, and thus which individuals will be born in the future. This is because all persons owe their existence to the coming together of a singular egg and a singular sperm - and this 'coming together' is highly sensitive to antecedent events. In fact, after a few generations, and depending on which policy we choose, completely different sets of people will come into existence and these sets of people will owe their existence to this prior choice (they would not have been born if this choice had not been made). Moreover, as we can predict with some accuracy that the adoption of neither policy will result in any of our distant successors leading lives which are not worth living, it appears that choosing Depletion over Conservation will not result in any particular future person being harmed. On the other hand, such a choice would benefit many in the present generation by doing so, as even the limited sacrifices which Conservation will demand of existing persons will be on balance harmful. It seems then that the policy that ought to be adopted is, perhaps counterintuitively, the Depletion Policy.

Is there an objection to this line of argument and, if so, what is it? The need to answer these questions gives rise to what has been called the non-identity problem $^{10}$ and the way in which we answer them will have great significance for the way in which we approach issues of environmental, and intergenerational, justice. Take Barry's resourcist view. The non-identity problem appears to pose a severe challenge for this view because it appeals to a strong connection between the requirements of justice on the one side, and the notions of harm and disadvantage on the other. Barry holds that failures to compensate future generations for deficits in the resource base they enjoy which are brought about by

\footnotetext{
${ }^{9}$ Various versions of this argument have been put forward, but by far the most influential is Parfit's. See D. Parfit, Reasons and Persons, (Oxford, Clarendon Press, 1984), pp.351ff.

${ }^{10}$ Parfit, Reasons and Persons, p.359.
} 
the actions of previous generations are unjust, and that they are unjust because such actions render people worse off than they otherwise would have been. But the non-identity problem demonstrates that there will be few, if any, cases where a future person will be rendered worse off by their ancestors' profligate emissions of GHGs, because these people would never have existed had these profligate actions not been performed.

This is not a problem which Barry's view faces alone. All views of intergenerational justice which endorse what has become known as the 'contractualist' view of morality will be prone to the non-identity problem. According to contractualism, the source of moral motivation is 'the desire to be able to justify one's actions to others on grounds they could not reasonably reject ${ }^{\prime 11}$ and an act is wrong only if its performance 'would be disallowed by any system of rules for the general regulation of behaviour which no one could reasonably reject as a basis for informed, unforced general agreement. ${ }^{12}$ For a person to reasonably reject (or raise a decisive objection to) an act or social policy on the contractualist view, this person must (1) be disadvantaged or harmed by it in some way and (2) they must have a complaint grounded in this disadvantage which is unanswerable (we might call this the Unanswerable Complaints Requirement). ${ }^{13}$

The problem with applying the unanswerable complaints requirement to the Conservation-Depletion choice, though, is that there appear to be no particular people here whom our acts will affect for the worse, and will thus have a complaint against us, if we choose Depletion. Moreover, as even mildly conservationist policies will require some sacrifices of existing persons, it seems that if any people have unanswerable complaints here it will be people who belong to the present generation (for example, those living in

\footnotetext{
${ }^{11}$ T.M. Scanlon, 'Contractualism and Utilitarianism', in A. Sen and B. Williams, eds., Utilitarianism and Beyond, (Cambridge, Cambridge University Press, 1982), p. 116.

${ }^{12}$ T.M. Scanlon, 'Contractualism and Utilitarianism', p.110. Barry endorses the contractualist view in both Theories of Justice, (Berkeley, University of California Press, 1989), pp. 284ff; and Justice as Impartiality, (Oxford, Clarendon, 1995), pp. 67-72. It is worth noting that Barry does not address the difficulties which the non-identity problem pose for his view in any of his published work on intergenerational and environmental justice, although in a recent article he does observe that contractual thinking cannot readily explain our duties to future persons or the non-human world. Thus he remarks that although 'the interests of people in the future should have no less weight than those of people in the present', it does not appear that 'the contractual apparatus is useful in this context; it throws up more problems than it solves.' See 'Contractual Justice: a Modest Defence', Utilitas, 8 (1996), p.365. Barry does not go on to state how he thinks we might reconcile contractualism with stringent duties of intergenerational justice, though it appears to be his desire to do so in the last of his three volume work $\underline{\text { A Treatise on Social Justice. }}$.

${ }^{13}$ See Parfit, Reasons and Persons, who observes that on the Scanlonian view 'an act cannot be wrong unless it will affect someone in a way that cannot be justified - unless there will be some complainant whose complaint cannot be answered' (p.523).
} 
the developing world who will suffer if their economies fail to keep growing) - and these complaints will be raised against the adoption of the Conservation Policy, not the Depletion Policy). ${ }^{14}$

I have focused, here, on the questions raised by the non-identity problem for theories of intergenerational justice, such as Barry's, which explicitly endorse the contractualist view. However, similar questions will be raised for numerous other theories which appeal, at least in part, to the way in which acts or social policies harm particular persons when they are extended to deal with questions of intergenerational justice. It would appear to call into doubt, for example, recent attempts to use Locke’s well-known second proviso - according to which acquisitions of natural resources must leave 'enough, and as good left in common for others' - to ground stringent requirements of environmental conservation. ${ }^{15}$

Theories such as these, which can be described as identity-dependent theories, direct us to make particular human beings, or animals, healthier or happier or rescue people from harm or disadvantage, particularly if these disadvantages arise through no fault of their own. Identity-dependent theories can be contrasted with identity-independent theories, according to which it can be wrong to perform acts or adopt social policies, even if they do not harm any particular persons. Such theories direct us to promote health or happiness, and to eliminate poverty or disease from an impersonal point of view (that is for reasons quite apart from the way in which particular individuals are affected by these phenomena).

One way of illustrating the dilemma that the non-identity problem poses for identity-dependent theories of environmental and intergenerational justice, is to note that it tempts the proponents of these theories into holding four, mutually inconsistent, beliefs. According to these beliefs:

\footnotetext{
${ }^{14}$ The possibility that climate change policies could well have as damaging an effect on the well-being of the present poor as they do beneficial effects for the well-being of future generations is raised by Beckerman and Malkin. The authors observe that 'Global warming is far more glamorous and telegenic, of course, than the need for better toilets and drains in the Third World. But if we truly care about the welfare of our fellow world citizens, it is these kinds of environmental issues upon which we must focus our attention.' See W. Beckerman and J. Malkin, 'How much does global warming matter?', The Public Interest, 114 (1994), pp.15-16.

${ }_{15}$ J. Locke, Two Treatises of Government, (London, Everyman, 1924), Book II, Ch.V, Sec. 27, p.130. See also R. Elliot, 'Future Generations, Locke's Proviso and Libertarian Justice', Journal of Applied Philosophy, 3 (1986), pp.217ff.
} 
(A) adopting the Depletion Policy is wrong.

(B) an act or social policy can be wrong only if it harms or disadvantages a particular person

(C) an act or social policy harms or disadvantages a particular person only if it makes them worse off than they would have been had the act not been performed

(D) the adoption of the Depletion Policy is a remote, but necessary, condition of the Depletion People coming into existence.

If we are inclined towards an identity-dependent view, it seems that we must abandon either belief B or C (or possibly both) if we are to construct an account which explains why choosing the Depletion Policy in the above case would violate some requirement of justice. ${ }^{16}$ However, both $\mathrm{B}$ and $\mathrm{C}$ appear to have a great deal of intuitive appeal. David Heyd, for example, has argued recently for the view that the price of abandoning either of these beliefs, and with them the identity-dependent view of justice, is simply too high. ${ }^{17}$ Endorsing a view which he calls generocentrism, Heyd claims that obligations of social justice only can be owed to persons whose identities lie beyond the reach of the non-identity problem. But because persons whose identities do not depend on present decisions will almost invariably belong to the present generation, Heyd claims that we have no obligations of justice to the vast majority of future individuals. If this rigidly identity-dependent view could be defended, it would appear that the non-identity problem has massive implications for both the nature of intergenerational and environmental justice. It implies, for example, that depletionist acts or social policies which result in the emission of huge amounts of GHGs into the atmosphere, and a lowering of the quality of life of future generations, are neither unjust nor immoral. ${ }^{18}$

\section{The limits of the non-identity problem}

\footnotetext{
${ }^{16}$ I put aside the possibility of revising belief $\mathrm{D}$ in order to retain beliefs A, B and C - a move which seems at the very least inconsistent with the pre-eminent theories of personal identity. See Parfit, Reasons and Persons, pp.351-55.

${ }^{17}$ Heyd, Genethics: Moral issues in the creation of persons, Berkeley, University of California Press, pp. $80 \mathrm{ff}$.

${ }^{18}$ It is worth noting that the non-identity problem appears to call into question the idea of obligations to both future humans and non-humans. This is because the identity of particular non-human animals will be as contingent on events which pre-date their existence as their future human counterparts.
} 
Even if we suppose that the non-identity problem is of relevance for debates about our obligations to future generations, and the issue of environmental justice in more general terms, it does appear that considerations of non-identity are not problematic for all theories of environmental concern. One way of explaining why this is the case is to see how the problem relates to different ways of theorising about the environment.

In what has become the standard taxonomy of such theorising, we might distinguish between anthropocentric, zoocentric, and ecocentric modes of environmental thought. ${ }^{19}$ Anthropocentric theories are those which attribute value only to states of human beings. One prominent example is the 'green theory of value' proposed by Robert Goodin. According to this view, the value of the natural world can be traced only 'to its value to human beings and the place it occupies in their lives. ${ }^{20}$

Zoocentric theories, by contrast, attribute value only to states of sentient creatures, including human beings. The idea here is that the desire to restrict the concerns of environmental justice to the well-being of human beings represents a sort of 'human chauvinism, ${ }^{21}$ which ignores the fact that species membership is essentially 'a morally irrelevant difference between individuals. ${ }^{22}$ According to Singer, for example, if we are committed to the fundamental principle that each human being's interests must be treated with equal concern and respect, we are also committed to accepting this principle of equality 'as a sound moral basis for relations with those outside our own species [such as] non-human animals. 23

Finally, ecocentric theories reject the idea that the natural environment is only valuable to the extent that it provides a context for the flourishing of humans or other sentient creatures. In contrast, this mode of thought presupposes that components of the

\footnotetext{
${ }^{19}$ See, for example, Brian Barry, Justice as Impartiality, pp.20ff.

${ }^{20}$ R. Goodin Green Political Theory, (Cambridge, Polity, 1992), pp.42-3. A similarly anthropocentric stance on the value of the natural environment is endorsed by the World Commission on Environment and Development's influential report Our Common Future,_(Oxford, Oxford University Press, 1987). In the foreword to this report, Gro Harlem Brundlandt argues that human well-being 'is the ultimate goal of all environment and development and development policies' (p.xiv).

${ }^{21}$ See R. and V. Routley, 'Against the Inevitability of Human Chauvinism', in Robert Elliot, ed., Environmental Ethics, (Oxford, Oxford University Press, 1995), pp.104ff.

${ }^{22}$ Elliot, Environmental Ethics, p.9.

${ }^{23}$ P. Singer, Practical Ethics, (Cambridge, Cambridge University Press, 1993), p.55.
} 
natural world such as plant life, and possibly the biotic community as a whole, possess value independently of humans or animals. ${ }^{24}$

I do not think it is necessary to take a stand on which of these modes of theorising best captures our concerns about the environment, or indeed intergenerational justice, in order to realise that the non-identity problem only calls into question the scope of certain varieties of anthropocentric and zoocentric (and possibly ecocentric) theorising, namely, those which appeal to ethical categories that make essential reference to how things are for particular individual humans, other sentient creatures, or particular natural objects. In short, the distinction between identity-dependent and identity-independent theories of justice cuts across the distinction between different ways of theorising about environmental concerns and values (of which the anthropocentric, zoocentric, and ecocentric views are the most widely discussed).

Nevertheless, there are at least three considerations which support the view that the non-identity problem is at least worthy of more attention than most environmental political philosophers have given it in recent years. First, even if we reject the view that identity-dependent theorising captures the whole of the story of intergenerational or environmental justice, it seems likely that it at least plays some part in this story. As a result it seems worth exploring the limits of such theorising.

Second, environmental theories which makes no reference to how things are for particular individual entities, such as impersonal utilitarianism or biotic holism, are highly contentious to say the least. Parfit, for example, has done much to demonstrate that applying identity-independent utilitarian principles to questions of intergenerational distribution leads to paradoxical results. ${ }^{25}$ Moreover, the idea behind biotic holism, that ethical standing be extended to components of the biosphere (such as rocks, trees, species of plant or animal life) - or even the biosphere as a whole - seems wildly counter-intuitive to many. ${ }^{26}$

\footnotetext{
${ }^{24}$ See P. Taylor, Respect for Nature, (New Jersey, Princeton University Press, 1986); K. Goodpaster, 'On being morally considerable', Journal of Philosophy, 78 (1978), pp.308ff.

${ }^{25}$ One problem which Parfit raises is that, in line with the duty to maximise social utility across generations, utilitarianism could require us to adopt environmental policies which lead to a huge number of people existing in the future who lead lives of poor overall quality instead of policies which lead to a much small number of people existing in the future who lead lives of a much higher quality. See Parfit, Reasons and Persons, pp.381ff.

${ }^{26}$ For criticism of the ecocentric view, see A. Brennan, 'Ecological Theory and Value in Nature', in R. Elliot, ed., Environmental Ethics, pp.195ff.
} 
Third, as noted earlier, much theorising about the environment and intergenerational justice remains stubbornly tied both to considerations of harm and vinctimhood on the one side, and the interests, needs, rights, and desires of particular sentient creatures on the other. This is revealed in the brief discussion of Barry's and Scanlon's views above, but an additional example of note arises from the work of Shue which specifically addresses the issue of climate change. Shue has claimed recently, for example, that we should conceive of the harmful effects of climate change as analogous to those of passive smoking, the idea being that both the activity of smokers, and of profligate emitters of GHGs, render other non-smokers and non-emitters worse off through no fault of their own. ${ }^{27}$ Shue, however, fails to acknowledge that the fact that future persons owe their very existence to the profligate actions of previous generations in these cases means that they cannot apparently complain that they have been harmed, or rendered worse off, by them. In this respect, the analogy between the effects of passive smoking on the one side, and the effects of depletionist policies on future generations on the other, seems unsound.

\section{Obligations to future collectivities}

In this section of the paper I propose that a limited appeal to the interests, rights, or moral value, of certain human (or possibly non-human animal) collectivities can solve the nonidentity problem in a limited, though important, range of cases; and as a result this appeal can explain, from an identity-dependent point of view, what is wrong with implementing policies which will have adverse long-term effects. I call views of intergenerational justice grounded in this appeal to human communities group-centred views. Group-centred views are special instances of identity-dependent views, such as Barry's or Scanlon's, which have been extended to include human (or animal) groups as being the subjects of moral consideration. these different views relate to each other is explored in figure 1 (page 14)

\section{Climate change and the claims of future collectivities}

The climate changes predicted by the IPCC and other researchers are expected to alter the cultural and social fabric of certain nations. There is possibly no better example of this

\footnotetext{
${ }^{27}$ Shue, ‘Avoidable necessity: Global Warming, International Fairness, and Alternative Energy’, pp.245-6.
} 
than the way in which these changes are expected to cause significant sea-level rises in the coming decades and centuries. In its latest assessment, the IPCC concluded that there will be an increase in global mean sea-levels of between $20 \mathrm{~cm}$ and $86 \mathrm{~cm}$ (with a 'best estimate' of $49 \mathrm{~cm}$ ) on 1990 levels by the year $2100 .{ }^{28}$ Moreover, it also predicts that this will have serious consequences for many nations in the future, but in particular for developing countries which are entirely, or have regions which are, low-lying. For example, these sea-level rises are expected to damage coastal cropland, and displace millions of persons from low-lying and coastal communities. Just some of the low-lying nations that the IPCC thinks are in most danger are the north-east coastal nations of Latin America, Bangladesh, Egypt and Holland. ${ }^{29}$

${ }^{28}$ See R.A. Warrick et al, 'Changes in Sea-level', in J. Houghton et al, eds., Climate Change 1995: The Science of Climate Change, p.385.

${ }^{29}$ See L. Bijlsma et al, 'Coastal Zones and Small Islands', in R.T. Watson et al, eds., Climate Change 1995: Impacts, Adaptations, and Mitigation of Climate Change, 289-324. The authors project that sea-level rise will have 'negative effects on a number of sectors, including tourism, freshwater supply and quality, fisheries and aquaculture, agriculture, human settlements, financial services, and human health’ (p.292). 


\section{Figure 1: Identity-Dependent and Identity-Independent Theories}

(Q1) Can an act be wrong if it does not affect any particular value bearing individual for the worse?

The Identity-Dependent View

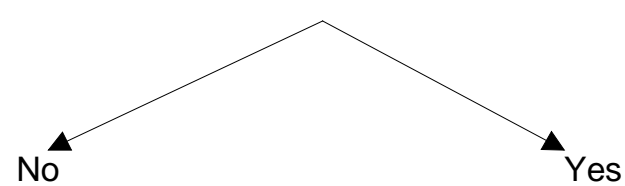

The Identity-Independent View

(Q2) Can an act be wrong if it affects a particular human or animal community (rather than any particular human or non-human animal) for the worse?

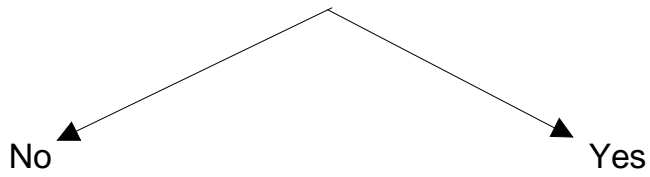

The Narrow Identity-Dependent

The Wide Identity-Dependent (or Individualistic) View (or Group-Centred) View

Perhaps the most disconcerting examples of nations vulnerable to sea-level rises, however, are the small island states of the South Pacific. The IPCC singles out these nations for special attention because of the especially, if not uniformly, adverse effects of sea-level rises on these states, including, in the worst case scenario, the possibility of complete disappearance. The combined effect of warming and sea-level rises on such states is expected to result in reduced soil fertility, reduced availability of agricultural land, and higher levels of soil erosion. It will be massively expensive to undertake even moderate adaptive responses for all of these effects, and even if the resources could be found (from international humanitarian assistance, for example) the costs to various communities in terms of maintaining access to traditional ways of life, and adapting to new ways of living, would be huge. These are all projections which the IPCC make with some confidence. ${ }^{30}$

${ }^{30}$ See Bijlsma et al, 'Coastal Zones and Small Islands’, pp. 296-98. See also E. Charles et al, A Future for Small States: Overcoming Vulnerability, London, Commonwealth Secretariat, 1997, pp.67ff. 
Suppose the IPCC's fears about the 'best estimate' figure of global sea-level rise of a half a meter by the year 2100 are proved accurate. Consider the case of

The Displaced Islanders. Towards the end of the 21st century, the elders of a Pacific island state have assembled to assess the damage which climate change has caused their small community. In line with the IPCC's projections, their island has been partially submerged by the Pacific Ocean, and their agricultural industry partially destroyed by a combination of soil erosion and soil infertility. Because of the lack of employment prospects and general social upheaval, moreover, the indigenous population has been cut to a small percentage of its twentieth century level. Finally, because of the combined impact of population displacement and other impacts, many cultural practices - practices which had been handed down through the generations - have been abandoned. The community, the elders agreed, was on the verge of collapse.

Let us put aside the economic, social and health impacts of climate change on existing islanders, and in particular the important issues of international justice which this case raises. Has the island community itself been harmed by - can a complaint be made on its behalf against - the failure of previous generations to implement GHG limiting policies which may have prevented the unsavoury effects of climate change imagined above? According to the group-centred view, there is at least some basis to say that it has. The idea is that, despite the fact that no particular islander who exists in the future where depletionist policies had been adopted would also have existed had conservationist policies been adopted, various island groups and associations would exist whichever sort of policy had been chosen, and the interests of these groups are deserving of concern and respect in their own right. Here it is the interests of the many groups whose existence and flourishing are bound up with the island's natural environment which generate certain moral requirements which we can say were violated by the Depletion Policy's adoption.

Suppose that the community was, prior to the sea-level rise, a traditional community dedicated to preserving a rich cultural and linguistic heritage. As the warming, and consequent sea-level rises, would result in the impoverishment of the islanders' 
linguistic and cultural heritage (most of the population bar the Elders, let us suppose, have fled to the mainland and now need to speak a different language in order to seek a living) the interests of the islanders as a collectivity might be thought to have been harmed by this. Because it assumes that there is inherent value in the survival of certain groups and that these groups possess valid moral claims qua groups, the group-centred view appears to avoid problems of non-identity. This is because the conditions of existence of many future groups (such as states, nations or cultures) will often be robust to the point that they will not be affected by environmental policy decisions made in the past. Obviously there are a number of simplifying assumptions being made here, such as the assumption that many of the adverse impacts of climate change on future populations can be prevented by the concerted efforts of present persons, governments and international institutions. However, the central idea - that climate change will in certain instances jeopardise the survival of certain communities and traditional patterns of life quite apart from the effects it will have on the individual members of these cultures - appears to be a plausible one. ${ }^{31}$

It is worth comparing the view proposed here with recent contributions to the issue of the rights or claims of minority cultures. It has recently been argued that the adoption of certain acts or social policies can be wrong by virtue of undermining the needs which particular individuals have to access a flourishing cultural or communal context within which to pursue their personal life-plans or conceptions of the good. For example, in his treatment of the issue of the claims of minority communities, Kymlicka argues that 'membership in a cultural structure is what enables individual freedom, what enables meaningful choices about how to lead one's life. ${ }^{32}$ Kymlicka goes on to claim that the moral importance of individual freedom is such that persons belonging to disadvantaged minority cultures should be afforded additional rights and resources to compensate for the disadvantages they face as a result of membership in a minority culture. But while these rights are collective, in the sense that they are exercised collectively rather than individually, they are nonetheless individual rights in the sense that they are grounded in the interests of particular persons. ${ }^{33}$ By contrast, according to the group-centred view, the

\footnotetext{
${ }^{31}$ The IPCC certainly think so, for they expect that 'adaptation to sea-level-rise and climate change will involve important trade-offs, which could include environmental, social, cultural values' (p.292).

${ }^{32}$ W. Kymlicka, Liberalism, Community, and Culture, (Oxford, Clarendon Press, 1989), p.208; and Multicultural Citizenship, (Oxford, Clarendon Press, 1995), pp.80ff.

${ }^{33}$ See Kymlicka, Multicultural Citizenship, pp.34ff.
} 
communities which future people will belong to are deserving of concern and respect in their own right; and if present actions have the result either that these communities die out altogether, or are damaged in the sense that various communal practices are undermined, they are morally objectionable at least in this one important respect. ${ }^{34}$

In this regard, the group-centred view shares much in common with Charles Taylor's work on multiculturalism and the politics of recognition, and in particular on the issue of the value of communities. Taylor denies that the worth of communities is derived from the value it has in securing the 'cultural needs' of individuals, such as their seeking to give meaning to their lives. He gives two reasons for this. First, Kymlicka's individualistic view neglects the moral importance of various communities qua communities. The idea here is that communities are often not merely associations of value-bearing individuals, but rather moral entities in their own right. Secondly, the individualistic view cannot make space for the way in which many persons have the intense desire that the community, or communities, they belong to continue to survive and flourish for reasons unrelated to the positive impact that this will have on their own wellbeing, or on the well-being of their compatriots taken as individuals. ${ }^{35}$ As such, Taylor argues that Kymlicka's individualistic view might be valid perhaps 'for existing people who find themselves trapped within a culture under pressure, and can flourish within it or not at all. But it doesn't justify measures designed to ensure survival through indefinite future generations. For the populations concerned, however, that is what is at stake. ${ }^{36}$ According to the terminology introduced earlier, and developed in figure 1, it appears that

\footnotetext{
${ }^{34}$ The idea of group-centred requirements of intergenerational justice might also be contrasted with the more obviously 'communitarian' idea that present persons should protect the conditions of communal flourishing because the communities which they belong to are in fact essential components of their identity as persons. Consider, for example, the communitarian theory of intergenerational justice defended in A. de Shalit's Why Posterity Matters, (London, Routledge, 1996), especially Ch.1. The idea is also to be contrasted with recent contributions to the 'deep ecology' mode of environmental thought, according to which duties of environmental conservation flow from the fact that human identity is not merely moulded by membership in human communities, but in addition by it's connection to natural processes and the biosphere itself. See, for example, W. Fox, Toward a Transpersonal Ecology, (Boston, Shambala, 1990). By contrast, the key to the group-centred view is the idea that adopting social policies which undermine the integrity or viability of certain human, or non-human animal, communities is morally regrettable because this fails to afford these communities with the respect that they deserve as moral entities, not that they are regrettable in virtue of undermining the motivations of self-transcendence entertained by existing human beings.

${ }^{35}$ C. Taylor, 'The Politics of Recognition', in A. Guttman, ed., Multiculturalism: Examining the Politics of Recognition, (Princeton, Princeton University Press, 1994), pp. 40-41.

${ }^{\frac{2}{36}}$ Taylor, 'The Politics of Recognition', p. 41.
} 
Taylor is advocating a widely identity-dependent (or group-centred) view to Kymlicka's narrowly identity-dependent (or individualistic) view.

One advantage associated with embracing the group-centred view is that, in virtue of retaining an identity-dependent structure, it appears readily reconcilable with the views of both Barry and Scanlon. Recall that, for Scanlon, an act is wrong only if its performance 'would be disallowed by any system of rules for the general regulation of behaviour which no one could reasonably reject as a basis for informed, unforced general agreement. ${ }^{37}$ It was argued above that contractualism and the unanswerable complaints principle this view of morality endorses, seem problematic in the context of non-identity cases such as the Depletion-Conservation choice, as the Depletion People, taken one by one, do not appear to have a legitimate complaint against the Depletion Policy's adoption.

However, contractualists do not appear to be committed to the idea that the complaints that they view as unanswerable must be restricted to those arising from harms, or wrongs, done to particular persons. This is demonstrated by Scanlon's understanding of the scope of contractualism, according to which (1) moral beings must possess a good in the sense that 'that there be a clear sense in which things can be said to go better or worse for that being', and (2) moral beings must 'constitute a point of view; that is there be such a thing as what it is like to be that being. ${ }^{38}$ These two conditions must hold, Scanlon thinks, for us to be able to hold that the notion of justification can be applied to an entity. But while there are certainly differences between the 'points of view' of particular human beings on the one side, and particular groups of human beings on the other, there seems to be no insurmountable barrier in the way of those who wish to argue that there can be such a thing as a group point of view, or perspective on things, or that things can go better or worse for at least some groups.

While I have not the space here to construct a more positive defence for this line of thought, it is worth mentioning that many peoples' moral intuitions certainly point in this direction. Consider, for example, the widespread intuition that the deaths of large numbers of persons from small indigenous communities (which result in the deaths of these communities) are more regrettable from the moral point of view than equivalent numbers of deaths of unrelated individuals. In any case, the suggestion is that we ought to think

\footnotetext{
${ }^{37}$ Scanlon, ‘Contractualism and Utilitarianism', p. 110.

${ }^{38}$ Scanlon, 'Contractualism and Utilitarianism', pp. 113-14.
} 
seriously about revising Scanlon's account of moral reasoning to read that 'an act is wrong only if it affects some particular individual or group in a way that cannot be justified.'

I have space to mention only one problem with using the group-centred view to explain how an identity-dependent objection to depletionist policies might be defended in the light of considerations of non-identity. Suppose that a course of action which we think will harm a certain future group's interests would also be a necessary condition of that group's existence. In such cases it might be that the approach will be plagued by a new group-centred version of the non-identity problem, which we might call the extended nonidentity problem. This new version of the non-identity problem suggests that a representative of some community who claims that the interests of their community had been harmed by the profligate environmental activities of past generations would encounter great problems in defending this view. In such circumstances it seems that the group-centred view could not be used to ground an identity-dependent objection to these activities; and as a result it would seem that only identity-independent considerations would stand in the way of the claim that it would not be wrong for depletionist policies to be adopted by existing generations.

It is, of course, worth noting that conditions of non-identity will obtain much less regularly in the case of groups than in the case of individual persons. This is because the identities of many groups and communities are more robust - nations, for example, typically outlive their individual members many times over. As a result, the extended nonidentity problem only partly rebuts the group-centred view. The conclusion we should take from this, I think, that this view does indeed offer at least some defence of an identitydependent environmental, and intergenerational, ethic. 